\title{
Pediatric Insomnia: Update and Future Directions
}

\author{
Lisa Medalie ${ }^{1}$ David Gozal ${ }^{2}$ \\ ${ }^{1}$ Departments of Pediatrics and Medicine, Pritzker School of \\ Medicine, University of Chicago, Chicago, Illinois, United States \\ ${ }^{2}$ Department of Child Health, University of Missouri School of \\ Medicine, Columbia, Missouri, United States \\ J Child Sci 2018;8:e172-e180.
}

Address for correspondence Lisa Medalie, PsyD, CBSM, Departments of Pediatrics and Medicine, Pritzker School of Medicine, University of Chicago, Chicago, IL 60637, United States (e-mail: Imedalie@bsd.uchicago.edu).

\begin{abstract}
Keywords

- pediatric

- insomnia

- review

Throughout their childhood, pediatric insomnia impacts approximately $25 \%$ of all children in the general population. Although it can occur as an isolated condition, it commonly associates with other comorbidities, such as autism, developmental delay, and psychiatric disorders. Careful and detailed history is essential, and sleep logs and actigraphy are useful tools in the assessment and diagnosis of pediatric insomnia. However, polysomnography is usually not warranted in the assessment of pediatric insomnia unless underlying medically-based sleep symptoms are concurrently identified and justify such test. In the majority of cases, behavioral interventions are the recommended approach for treatment. Despite the fact that many pharmacological approaches are used for child insomnia off-label, there are currently no FDA (Food and Drug Administration) approved medications for the management of pediatric insomnia. The high prevalence of pediatric insomnia, coupled with the low number of providers, who are formally trained in behavioral treatment for this prevalent condition, highlights the urgent need for improving primary care practitioner awareness, while expanding alternative routes to access to care, such as interactive virtual technology-based treatments, parent education and manuals, along with ongoing efforts to increase professional training opportunities.
\end{abstract}

\section{Introduction}

There is little if any doubt that adequate sleep is an essential ingredient of wellness and the enhanced sleep needs manifested by developing children further attest to the importance of this physiological state in optimal growth and intellectual and emotional development. However, the naturally occurring rhythms of wake-sleep in children undergo substantial age-dependent changes that frequently conflict with established activity patterns of their parents. Furthermore, the complex dynamics of physical and emotional interactions between child, parents, and environment are susceptible to disruption and can easily lead to suboptimal sleep for anyone in the dyad. When suboptimal sleep devel- ops a chronic longer lasting pattern, the diagnostic concept of insomnia needs to be invoked and pursued to identify the factors and trigger underlying such issue and proceed with the necessary interventional steps that will lead to a return to the optimal equilibrium of sleep and waking for each of the family members.

The purpose of this review is to summarize the current literature pertaining to pediatric insomnia. ${ }^{1}$ To achieve a common terminology, we will start by explaining what we mean when we use the term "pediatric insomnia." Generally speaking, insomnia refers to having trouble falling asleep, staying asleep, or both. As a result, insomnia sufferers may get too little sleep or have poor-quality sleep. However, insomnia can be acute or chronic, with acute insomnia often received

August 29, 2018

accepted after revision

September 4, 2018
DOI https://doi.org/

$10.1055 / \mathrm{s}-0038-1675222$.

ISSN 2474-5871.
Copyright @ 2018 Georg Thieme Verlag License terms

KG Stuttgart · New York

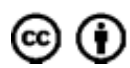


being brought on by situations such as stress, acute illness, or any other perturbation, and usually lasting for a few days or weeks. By definition according to the last iteration of the third International Classification of Sleep Disorders (ICSD-3), the problem occurs at least three times per week, and the sleep disturbance and associated daytime symptoms have been present for at least 3 months. ${ }^{2}$ In this context, the patient reports, or the patient's parents or caregivers observe, one or more of the following:

- Difficulty initiating sleep.

- Difficulty maintaining sleep.

- Waking up earlier than desired.

- Resistance going to bed on appropriate schedule

- Difficulty sleeping without parent or caregiver intervention

Importantly, the reported sleep/wake complaints cannot be explained purely by inadequate opportunity (i.e., enough time allotted for sleep) or inadequate circumstances (i.e., the environment is safe, dark, quiet, and comfortable) for sleep.

In ICSD-2, the term "Behavioral Insomnia of Childhood, Sleep Onset Association Type" was used to describe children who learned to fall asleep through behaviorally established pattern associated with external conditions. For example, those children who fell asleep being rocked by a caretaker or held in the arms by a parent, and then struggle to return to sleep without a parent present or without continued rocking motion were defined by this diagnosis. Children who struggled to follow bedtime rules and exhibited protests or tantrums at bedtime were diagnosed with "Behavioral Insomnia of Childhood, Limit Setting Type." Children exhibited features of both conditions were diagnosed with "Behavioral Insomnia of Childhood, Combined Type." 3

Behavioral Insomnia of Childhood diagnoses were often used to describe the sleep challenges in younger children. Older children and teenagers often exhibited symptoms more closely resembling adult challenges. The International Classification of Sleep Disorders, second edition, used the term psychophysiological insomnia to describe those who experienced a cycle where sleep struggles would evoke a state of physiological, cognitive, and emotional arousal which would then create more insomnia. ${ }^{3}$ While this diagnosis is more commonly used to describe adult patients, many pediatric insomnia providers also used this diagnosis to describe older children and teenagers presenting with such symptoms. However, studies showed that when large groups of providers diagnosed the same patients, poor diagnostic consistency emerged, ${ }^{4}$ prompting the need for consensus documents. ${ }^{5}$ Therefore, ICSD-3 was released in 2014 which changed the approach to diagnosing insomnia. As mentioned above, the current classification manual uses insomnia disorder to describe difficulties falling asleep or returning to sleep in children and adults. This disorder is only diagnosed in the context of adequate sleep opportunity and resulting distress or functional impairment. The specification "acute" is utilized for those who present symptoms less than 3 months and report symptom resolution when the triggering stressor resolves. The term "chronic" is utilized for those who report symptoms at least three nights per week for at least 3 months. They include an "other" specification option for those who do not fit into acute or chronic diagnostic criteria. While the Behavioral Insomnia of Childhood and Psychophysiological Insomnia diagnoses are no longer listed in the manual, many providers still utilize the former approaches to explain or describe insomnia and conceptualize cases. Such descriptions illustrate the struggle of the patients and their families and help explain the rationale for behavioral treatment strategies.

\section{Prevalence}

Pediatric insomnia impacts approximately $25 \%$ of children in the general population. 6,7 Owens and colleagues ${ }^{8}$ found that insomnia was reported in almost one third of patients referred for evaluation to a psychiatrist. Insomnia complaints are also reported in $10.7 \%$ of adolescents, ${ }^{9}$ a prevalence that is remarkably similar to the estimated 6 to $10 \%$ of adults meeting criteria for chronic insomnia. ${ }^{10,11}$ However, insomnia in children is often an underdiagnosed condition in primary care settings, further attesting to the need for additional education and support of primary care providers in the diagnosis and treatment of pediatric sleep disorders. ${ }^{12}$ Furthermore, significant interactions between gender and age are apparent in school age children, such that the prevalence of insomnia symptoms is highest in girls aged 11 to 12 years (approximately 30\%). ${ }^{13,14}$ We should however emphasize that insomnia does not include children who simply suffer from poor sleep hygiene issues in the household and whose habits result in insufficient sleep duration, even if the latter is increasingly prevalent in the context of explosive increase in screen use including at bedtime. $^{15,16}$

\section{Etiology}

Owens and Moore ${ }^{17}$ summarized the intrinsic and extrinsic factors that associate with an increased risk of insomnia in children. Intrinsic factors are predisposing elements and inborn features of the child that promote potential behaviors which if persistent my translate into the typical phenotype of insomnia. ${ }^{18}$ If a baby is born with a colicky temperament, this can create an intrinsic vulnerability for sleep troubles. ${ }^{19}$ Medical issues, such as gastroesophageal reflux, atopic dermatitis, periodic legs, sleep apnea, or milk allergies are all factors that can interfere with sleep continuity and trouble sleep architecture. An inborn delayed or advanced circadian clock tendency can impact the rhythmicity and timing of melatonin secretion patterns and promote the misalignment that favors the occurrence of insomnia. Developmental delay and psychiatric comorbidities (e.g., Autism, Attention Deficit Hyperactivity Disorder, 
Generalized Anxiety Disorder) can all foster delayed or dysfunctional learning of self-soothing which may also result in troubles with sleep onset or sleep maintenance that may persist well into adolescence and beyond (see - Figs. 1, 2). ${ }^{20-22}$ In contrast, "extrinsic factors" are defined as environmental aspects or patterned caregiver responses that can promote the occurrence and perpetuation of insomnia in children. An important facet of such factors resides in the presence of medical or psychiatric disorders in a caregiver and transfer of some behavioral cues to their children, such as ultimately increasing the risk of sleep problems when their response to children during the night is impacted by their own struggles. Inconsistent parenting styles induce intermittent reinforcement of sleep behaviors which can also result in difficulty with the acquisition of consistent sleep onset maintenance for children. Living conditions, such as shared or distracting bedroom environments can increase the risk of insomnia in children as well. ${ }^{23}$

\section{Impact}

Children with sleep difficulties experience multiple related consequences. $^{24,25}$ From a mood standpoint, children with insomnia, similar to adults, are more vulnerable to irritability and frustration intolerance and such effects may persist for many years. ${ }^{26}$ Those who struggle with psychiatric symptoms (e.g., depression and anxiety) are at increased risk for such symptoms following nights with insomnia symptoms. Academic consequences are also a well-docu- mented effect of sleep loss or insomnia. Children experience cognitive effects from insufficient sleep which likely play a significant role in such performance effects. ${ }^{20}$

Children with insomnia may also experience adverse cognitive and behavioral impact that closely mirrors symptoms of Attention-Deficit/Hyperactivity Disorder (ADHD). While adults with insomnia may present as slow or lethargic as a result of sleep loss, children often present with hyperactivity. As a result, children are at risk for being misdiagnosed with ADHD if proper screening of sleep disorders is not conducted leading to escalation of poor health. ${ }^{28}$

Parent stress can also result from insomnia in children. Indeed, poorer physical and mental health is found in parents of children with insomnia compared with controls. ${ }^{29}$

\section{Assessment}

The standard approach to assessment of pediatric insomnia starts with a thorough and detailed clinical interview. ${ }^{30}$ An in-depth developmental, medical, and psychiatric history, as well as exclusion of medically-based sleep symptoms, is mandatory during the clinical interview (for a brief schematic guide see - Figs. 1, 2). Particular emphasis on collection of sleep schedules information, sleep habits, bedtime routines, and characteristics of the sleep environment are all integral components of the clinical interview pertaining to pediatric insomnia.

Subjective measures can also be utilized to assess pediatric insomnia. A study conducted by Ivanenko and colleagues $^{31}$ found that the majority of children with insomnia

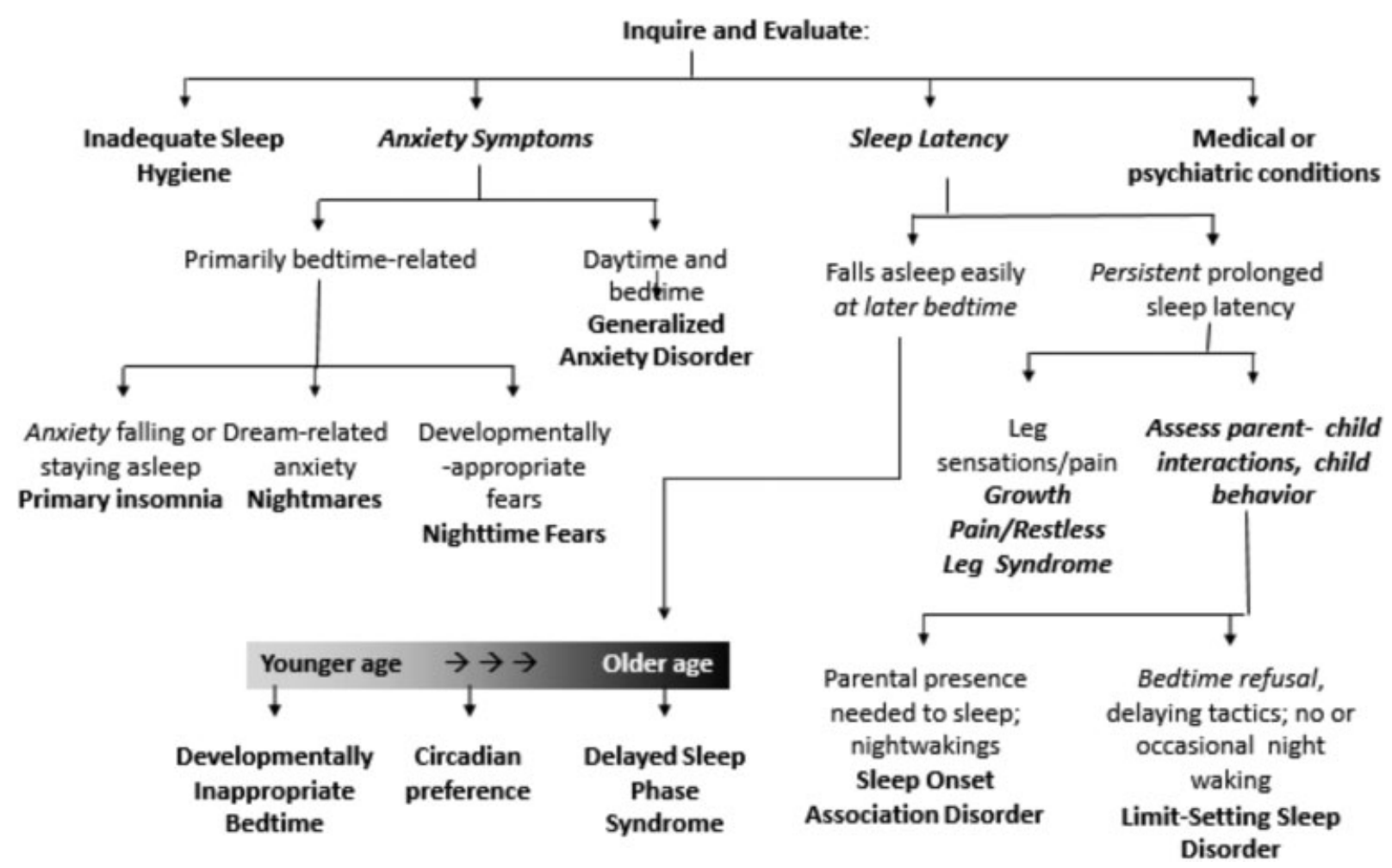

Fig. 1 Proposed approach to bedtime resistance or prolonged sleep latency in children (modified from Owens and Moore, 2017). 


\section{Evaluation and Management of Frequent Night Waking}

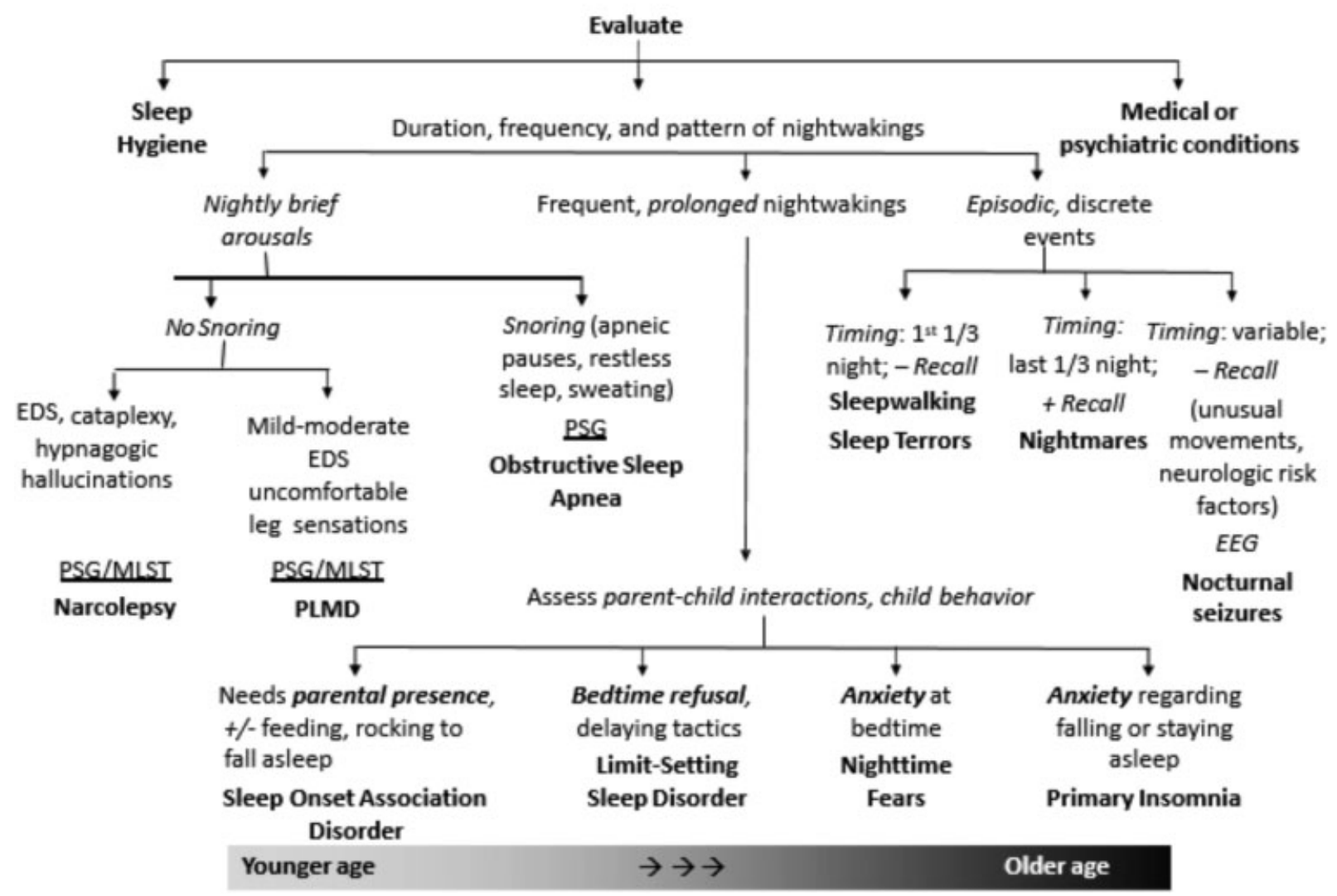

Fig. 2 Proposed approach to evaluation and management of frequent night waking in children (modified from Owens and Moore, 2017)

present with concurrent psychiatric symptoms. They list the following scales as options for assessing psychiatric symptoms in this population: behavior-assessment system for children (BASC), pediatric symptom checklist (PSC), and clinical attention problem scale (CAPS). Use of the Children's Sleep Habits Questionnaire ${ }^{32}$ and the Pediatric Insomnia Severity Index ${ }^{33}$ are also commonly utilized to assess insomnia in children. Additional tools have also emerged for specific evaluation of pediatric insomnia in different age groups and the current advice would be to critically appraise such tools in the context of the local practice, such as to improve their consistency, reliability, and value in the longterm follow-up of the patients. ${ }^{34}$

Sleep diaries are typically provided at the culmination of the initial visit with an insomnia patient. Sleep diaries are logs in which parents' track their "best guess" about what happened the night before with their child's sleep. Sleep onset latency, wake after sleep onset, time in bed, total sleep time, and sleep efficiency can be estimated from the sleep diary. Such data are often calculated on a weekly basis during treatment to compare pretreatment features numbers to intratherapy averages and provide families and the clinician with some feedback estimate on whether treatment is effective or not.

Actigraphy is a commonly used objective tool in the assessment of pediatric insomnia. Actigraphic devices are wrist-worn motion detection systems (accelerometers) and provide reliable degrees of sleep estimates even if their accuracy is fraught with limitations. ${ }^{35-39}$ After the patient wears the actigraphic device for approximately 2 weeks, data are downloaded through custom software whereby a validated algorithm enables inferential decisions of sleep versus wake, such as to generate a summary of estimated sleep characteristics on a nightly basis. In addition to charts with data summaries, families, and referral sources are provided with a visual depiction of sleep-wake patterns (i.e., actogram). Dayyat et $\mathrm{al}^{36}$ compared the accuracy of parent estimates via sleep diaries to objective tracking via actigraphy. They found that while parents effectively described symptoms of insomnia using sleep diaries, accuracy of sleep onset latency and total sleep time as estimated by parents was quite limited when compared with actigraphy.

As a rule of thumb, overnight polysomnography is not indicated in the assessment of pediatric insomnia. ${ }^{40}$ During the clinical interview, if patients report symptoms of sleep apnea or medically-based sleep disorders, polysomnography is then deemed appropriate. When the clinician suspects such symptoms are causing the patient's insomnia complaints, the sleep study is often ordered prior to treating insomnia and insomnia treatment can be delayed or 
cancelled if medical treatment addresses such complaints. If the insomnia complaints preceded the medically-based symptoms and are suspected as constituting separate entities, initiation of insomnia treatment concurrent with the evaluation of medically-based sleep disorders is often pursued.

\section{Treatment}

Behavioral treatment is the current recommendation for first line treatment of pediatric insomnia. ${ }^{41}$ Recent meta-analysis evaluating eligible studies of Cognitive Behavioral Treatment for Insomnia (CBT-I) with children and adolescents consistently found that CBT-I significantly improved sleep onset latency and sleep efficiency in children and adolescents with chronic insomnia. ${ }^{42-51}$

Meltzer provided a detailed summary of how to apply evidence-based behavioral strategies for insomnia in young children $^{52}$ (2010). She described the importance of a consistent sleep schedule and consistent bedtime routine for all children. She also reviewed use of standard extinction or graduated extinction protocols for children with sleep onset association insomnia (e.g., learned to fall asleep with a parent present). Meltzer explained that standard extinction involves putting a child down awake but drowsy and not returning until morning (ignoring all crying and protests). Graduated extinction incorporates a slow removal of parent presence (e.g., moving further away from the bed every few nights and incorporation of scheduling checks at increasing time intervals). To address limit-setting issues, she described use of reinforcement programs and behavior charts to encourage desired behavior as well as active ignoring of unwanted behavior. ${ }^{52}$

As mentioned in a review by Tikotzky and Sadeh, ${ }^{53}$ insomnia in older children or adolescents is often resembles symptoms presented by adults. A focus on use of similar strategies utilized for adults is also discussed. The American College of Physicians released a paper in 2016 stating that Cognitive Behavioral Treatment for Insomnia (CBT-I) is the first line recommendation for chronic insomnia. ${ }^{54}$ Use of sleep hygiene, sleep restriction, stimulus control, relaxation strategies, and cognitive sessions (e.g., worry-time and cognitive restructuring) are utilized in CBT-I (- Table 1). Pediatric versions of these strategies have been developed to address age-related needs ( - Table 2 ). In addition, web-based interventions are also gaining popularity in light of their relative success. ${ }^{55-57}$

A Committee focused on Practice Parameters from the American Academy of Sleep Medicine reviewed 52 treatment studies pertaining to behavioral treatments of pediatric insomnia. They found that $94 \%$ of studies showed clinically significant improvements in the context of behavioral interventions. Improved symptoms were found in $82 \%$ of participants studied. ${ }^{41}$ While behavioral treatment is evidencebased, use of medication is not yet approved for the treatment of insomnia in children. Stojanovski et $\mathrm{al}^{58}$ found that $81 \%$ of pediatric psychiatry visits resulted in prescription of medication for pediatric sleep complaints. This is particu- larly an alarming given that the FDA (Food and Drug Administration) has not yet approved any medication for treatment of insomnia in children, even if many drugs are currently prescribed off-label for insomnia in children. ${ }^{59-61}$ While prescription medication has not been approved, evidence form published studies in the past 15 years supports the overall efficacy and tolerability of melatonin for insomnia in children. ${ }^{62-66}$ Melatonin is considered particularly beneficial for insomnia in children with autism ${ }^{67,68}$ or special needs. ${ }^{69,70}$

\section{Future Directions}

Pediatric insomnia is a highly prevalent condition (25\% of children struggle with sleep ${ }^{7}$ ). Children with sleep problems experience mood disturbances, academic challenges, and exhibit symptoms closely resembling ADHD, leading to high risk for misdiagnosis of ADHD with resultant prescription of stimulant medication which can ultimately pose increased risk for sleep disturbance. Parents of children with insomnia are often highly distressed and experience sleep loss creating a vicious cycle of stress and despair.

Parent stress can be a significant factor when working with children with insomnia. ${ }^{29}$ As parents are also in the treatment room during the visit, such factors are extremely important when conceptualizing and treating children with insomnia. Parents bring their child for treatment (sometimes unwillingly or unknowingly). Given the high distress and sleep loss experienced by the parent, their emotional clarity is not always present and can obfuscate the decision process. They may not be willing to admit or accept their participation or contribution to the symptoms. Therefore, childhood insomnia can be challenging to treat because the child is not self-motivated and did not initiate treatment, and the distressed parent may not be willing to take ownership for their role and agree to make necessary changes in their routines and behaviors to treat the symptoms. Further research pertaining to strategies for addressing such barriers (e.g., motivational enhancement) is therefore warranted.

Assessment and treatment for pediatric insomnia is wellvalidated. We use clinical interview, sleep logs, screening tools and often actigraphy to assess pediatric insomnia. Prescription medication is not currently approved by the FDA for insomnia in children, yet medication is prescribed at alarmingly high rates with minimal if any critical evidence supporting efficacy and weighed risks versus benefits. However, behavioral treatment for pediatric insomnia is considered effective with no known risks or side effects.

Unfortunately, the number of experts trained in the diagnosis and treatment of pediatric insomnia is vanishingly small around the world, with currently less than 20 child psychologists being formally trained and certified in behavioral sleep medicine. This is concerning, given the prevalence and impact of pediatric insomnia. Several training programs are now emerging and offering training to those interested in this career pathway which gives hope for the future of improved access to care. That said the 
Table 1 Cognitive behavioral treatment for insomnia-overall strategies

\begin{tabular}{|c|c|c|}
\hline \multicolumn{3}{|c|}{ Cognitive behavioral treatment for insomnia (CBT-I) } \\
\hline Session strategy & Rationale & Treatment components \\
\hline Sleep hygiene & - Poor sleep habits exacerbate insomnia & $\begin{array}{l}\text { - Turn off electronics } 1 \mathrm{~h} \text { before bedtime } \\
\text { - Stop exercise } 3 \mathrm{~h} \text { before bedtime } \\
\text { - Avoid heavy or spicy foods } 3 \mathrm{~h} \text { before } \\
\text { bedtime } \\
\text { - White noise and blackout shades } \\
\text { - Relaxing pre-sleep ritual } \\
\text { - Avoid caffeine } 8-10 \text { h before bedtime } \\
\text { - Sleep in a cool temperature room }\end{array}$ \\
\hline Sleep restriction & $\begin{array}{l}\text { - Reduced time in bed increased sleep drive } \\
\text { or sleep pressure } \\
\text { - Increased sleep drive or sleep pressure } \\
\text { deceases insomnia }\end{array}$ & $\begin{array}{l}\text { - Collect baseline average total sleep time } \\
\text { from sleep diaries or sleep logs } \\
\text { - Prescribe time in bed based on estimated } \\
\text { average total sleep time at baseline } \\
\text { - Prescribed time in bed can anchor at the } \\
\text { earliest documented wake time } \\
\text { - Calculate sleep efficiency (i.e., percentage } \\
\text { of time sleeping relative to time in bed) and } \\
\text { total sleep time using sleep diaries or sleep } \\
\text { logs at each subsequent visit } \\
\text { - Add } 20 \text { min to sleep window each week } \\
\text { where significant increase in sleep effi- } \\
\text { ciency is documented (e.g., often aiming } \\
\text { for } 85-90 \% \text { sleep efficiency) }\end{array}$ \\
\hline Stimulus control & $\begin{array}{l}\text { - Classical conditioning based on Pavlovian } \\
\text { theory explains the perpetuation of } \\
\text { insomnia } \\
\text { - Repeated pairing of the bed plus wakeful- } \\
\text { ness, thinking or emotional distress ulti- } \\
\text { mately leads the bed to cue a state of } \\
\text { wakefulness, thinking, or emotional distress }\end{array}$ & $\begin{array}{l}\text { - Stay out of the bed from wake time to } \\
\text { bedtime } \\
\text { - If it has been } 15-20 \text { min (or as soon as } \\
\text { emotional distress is experienced), get out } \\
\text { of bed and read a book or magazine for 5- } \\
10 \text { min } \\
\text { - Get out of bed after } 5-10 \text { min of reading } \\
\text { - If you get back to bed and again struggle } \\
\text { with sleep, go back out of the bed and read } \\
\text { again } \\
\text { - Use this approach at the start of the night, } \\
\text { in the middle of the night and for early } \\
\text { morning awakenings }\end{array}$ \\
\hline Relaxation strategies & $\begin{array}{l}\text { - Increased somatic arousal interferes with } \\
\text { sleep transition }\end{array}$ & $\begin{array}{l}\text { Diaphragmatic breathing: slowly inhale } \\
\text { through the nose for } 3-4 \mathrm{~s} \text { while belly expands, } \\
\text { hold the breath expanded for } 1-2 \mathrm{~s} \text {, and then } \\
\text { slowly exhale through the mouth for } 3-4 \mathrm{~s} \\
\text { while belly falls } \\
\text { Positive imagery: Imagine yourself in a scene } \\
\text { that gives a feeling of calm and relaxation; } \\
\text { picture all sensory experiences of that scene; } \\
\text { when the mind wanders, gently redirect to the } \\
\text { scene } \\
\text { Progressive muscle relaxation: Go through } \\
\text { each muscle group, starting with your legs and } \\
\text { moving slowly up to your forehead, and tense } \\
\text { for } 7 \mathrm{~s} \text { then relax for } 7 \mathrm{~s}\end{array}$ \\
\hline Worry-time & $\begin{array}{l}\text { - Worry or problem-oriented thoughts com- } \\
\text { monly arise when struggling for sleep } \\
\text { - Many people keep so busy throughout the } \\
\text { day that worry or problem thoughts are } \\
\text { insufficiently thought through } \\
\text { - Worry or problem thoughts evoke emo- } \\
\text { tional reactions which then interfere with } \\
\text { sleep }\end{array}$ & $\begin{array}{l}\text { - Schedule time to sort through worries or } \\
\text { problems at least } 3 \text { h before bedtime } \\
\text { - Get all thoughts out of your head and onto } \\
\text { paper to decrease the likelihood of such } \\
\text { thoughts interfering with sleep } \\
\text { - After listing out possible worry or problem } \\
\text { thoughts that might come up that night, list } \\
\text { out } 2-3 \text { possible ways to solve or cope with } \\
\text { each problem and then list out the most }\end{array}$ \\
\hline
\end{tabular}

(Continued) 
Table 1 (Continued)

\begin{tabular}{|l|l|l|}
\hline Cognitive behavioral treatment for insomnia (CBT-I) & Treatment components \\
\hline Session strategy & Rationale & $\begin{array}{l}\text { reasonable solution and how to execute } \\
\text { that solution or plan }\end{array}$ \\
\hline Cognitive restructuring & $\begin{array}{l}\text { - Aaron Beck explained that how we think } \\
\text { effects how we feel and what we do; he } \\
\text { called this the cognitive triad } \\
\text { Irrational or illogical thoughts during the } \\
\text { day evoke extensive or exacerbated emo- } \\
\text { tional reactions } \\
\text { Intense emotional states during the day can } \\
\text { increase the likelihood of insomnia during } \\
\text { the night }\end{array}$ & $\begin{array}{l}\text { - Learn to identify when you are experiencing } \\
\text { a cognitive error } \\
\text { - Label the thought according to a list of } \\
\text { common cognitive errors } \\
\text { Identify the emotion and percent intensity } \\
\text { of that emotion which is provoked by the } \\
\text { cognitive error } \\
\text { ist facts that support the thought is true } \\
\text { List facts that dispute the accuracy of that } \\
\text { thought } \\
\text { Identify a balanced replacement thought } \\
\text { based on such facts } \\
\text { Identify your emotional response and per- } \\
\text { cent intensity of the emotional reaction to } \\
\text { the replacement thought }\end{array}$ \\
$\begin{array}{l}\text { Maintenance and } \\
\text { relapse prevention }\end{array}$ & $\begin{array}{l}\text { Patients with insomnia are often vulnerable } \\
\text { to relapse of insomnia } \\
\text { sors and problems which initially precipi- } \\
\text { tated insomnia }\end{array}$ & $\begin{array}{l}\text { Identify possible triggers to relapse of } \\
\text { insomnia } \\
\text { Develop a plan for minimizing and addres- } \\
\text { sing possible relapse }\end{array}$ \\
\hline
\end{tabular}

Table 2 Pediatric oriented modifications of CBT-I approaches

\begin{tabular}{|c|c|}
\hline \multicolumn{2}{|l|}{ Pediatric modifications to CBT-I strategies } \\
\hline CBT-I Strategy & Pediatric Modification \\
\hline Sleep restriction (see $\mathbf{-}$ Table $\mathbf{1}$ ) & $\begin{array}{l}\text { Faded bedtime } \\
\text { - Instead of prescribing a time in bed coinciding with the total sleep time from the } \\
\text { baseline week, the bedtime is simply pushed back later for children } \\
\text { - This approach often utilizes less restriction to the prescribed sleep window } \\
\text { - Each week, the bedtime is advanced with improved sleep efficiency }\end{array}$ \\
\hline Stimulus control (see - Table 1) & $\begin{array}{l}\text { Response cost } \\
\text { - Instead of having the child decide when to get out of bed and read, the parent is } \\
\text { involved in the process } \\
\text { - The parent checks on the child after } 15-20 \mathrm{~min} \text { and if the child is awake they have } \\
\text { the child get out of bed and read for } 5-10 \mathrm{~min}\end{array}$ \\
\hline Relaxation strategies (see $\boldsymbol{- T a b l e ~} \mathbf{1}$ ) & $\begin{array}{l}\text { - Parents are involved by reading scripts and working with children to ensure } \\
\text { effective use of strategies } \\
\text { - "Child-friendly" terminology is utilized in the script (e.g., instead of "tensing your } \\
\text { hands and arms," "imagine you are squeezing a lemon") }\end{array}$ \\
\hline Worry-time (see - Table 1) & $\begin{array}{l}\text { - Parents are involved by sitting down with children and asking the questions from } \\
\text { the handout } \\
\text { - Sometimes children can draw their worries instead of writing them out }\end{array}$ \\
\hline Cognitive restructuring (see $\mathbf{- T a b l e ~} \mathbf{1}$ ) & $\begin{array}{l}\text { - Parents are involved by working with children to identify thoughts and emotions } \\
\text { - "Child friendly" terminology is utilized for cognitive errors and chart columns } \\
\text { - Pictures and coloring sheets can be integrated (e.g., child colors in how much of } \\
\text { the "emotional thermometer" they initially feel when the thought error is present } \\
\text { and then color in a how much of the new "emotional thermometer" they feel } \\
\text { following identification of a replacement thought) }\end{array}$ \\
\hline
\end{tabular}


immediate need is abundant. To circumvent the dire need for CBT-I delivery, several groups are investigating internetbased behavioral interventions which could certainly be a more immediate step toward increased access to care. ${ }^{46-74}$ Future endeavors geared toward increased access to care via technology and parent-friendly books are certainly warranted, as well as ongoing efforts to train professionals to effectively deliver behavioral treatment for pediatric insomnia, all of which should solidify improved access to care and provide respite to the insomniac child, his or her parents, and the primary care practitioners whose training and expertise is clearly exceeded by the demands of childhood insomnia.

\section{References}

1 Badin E, Haddad C, Shatkin JP. Insomnia: the sleeping giant of pediatric public health. Curr Psychiatry Rep 2016;18(05):47

2 American Academy of Sleep Medicine. The international classification of sleep disorders, 3rd ed. Darien, IL: American Academy of Sleep Medicine; 2014

3 American Academy of Sleep Medicine. The international classification of sleep disorders, 2nd ed. Darien, IL: American Academy of Sleep Medicine; 2005

4 Edinger JD, Wyatt JK, Stepanski EJ, et al. Testing the reliability and validity of DSM-IV-TR and ICSD-2 insomnia diagnoses. Results of a multitrait-multimethod analysis. Arch Gen Psychiatry 2011;68 (10):992-1002

5 Pin Arboledas G, Soto Insuga V, Jurado Luque MJ, et al. [Insomnia in children and adolescents. A consensus document]. An Pediatr (Barc) 2017;86(03):165.e1-165.e11

6 Honaker SM, Meltzer LJ. Sleep in pediatric primary care: a review of the literature. Sleep Med Rev 2016;25:31-39

7 Owens J. Classification and epidemiology of childhood sleep disorders. Prim Care 2008;35(03):533-546, vii

8 Owens JA, Rosen CL, Mindell JA, Kirchner HL. Use of pharmacotherapy for insomnia in child psychiatry practice: a national survey. Sleep Med 2010;11(07):692-700

9 Johnson EO, Roth T, Schultz L, Breslau N. Epidemiology of DSM-IV insomnia in adolescence: lifetime prevalence, chronicity, and an emergent gender difference. Pediatrics 2006;117(02):e247-e256

10 Ohayon MM. Epidemiology of insomnia: what we know and what we still need to learn. Sleep Med Rev 2002;6(02):97-111

11 Buysse DJ. Insomnia. JAMA 2013;309(07):706-716

12 Meltzer LJ, Johnson C, Crosette J, Ramos M, Mindell JA. Prevalence of diagnosed sleep disorders in pediatric primary care practices. Pediatrics 2010;125(06):e1410-e1418

13 Calhoun SL, Fernandez-Mendoza J, Vgontzas AN, Liao D, Bixler EO. Prevalence of insomnia symptoms in a general population sample of young children and preadolescents: gender effects. Sleep Med 2014;15(01):91-95

14 Fernandez-Mendoza J, Calhoun SL, Vgontzas AN, et al. Insomnia phenotypes based on objective sleep duration in adolescents: depression risk and differential behavioral profiles. Brain Sci 2016;6(04):E59

15 Gozal D. Sleep and electronic media exposure in adolescents: the rule of diminishing returns. J Pediatr (Rio J) 2017;93(06):545-547

16 Kohyama J, Anzai Y, Ono M, et al. Insufficient sleep syndrome: an unrecognized but important clinical entity. Pediatr Int 2018;60 (04):372-375

17 Owens JA, Moore M. Insomnia in infants and young children. Pediatr Ann 2017;46(09):e321-e326

18 Barclay NL, Gehrman PR, Gregory AM, Eaves LJ, Silberg JL. The heritability of insomnia progression during childhood/adolescence: results from a longitudinal twin study. Sleep 2015;38 (01):109-118
19 Li L, Ren J, Shi L, et al. Frequent nocturnal awakening in children: prevalence, risk factors, and associations with subjective sleep perception and daytime sleepiness. BMC Psychiatry 2014;14:204

20 Becker SP, Sidol CA, Van Dyk TR, Epstein JN, Beebe DW. Intraindividual variability of sleep/wake patterns in relation to child and adolescent functioning: a systematic review. Sleep Med Rev 2017; 34:94-121

21 Bruni O, Sette S, Angriman M, et al. Clinically oriented subtyping of chronic insomnia of childhood. J Pediatr 2018;196:194-200.e1

22 Fernandez-Mendoza J, Li Y, Fang J, et al. Childhood high-frequency EEG activity during sleep is associated with incident insomnia symptoms in adolescence. J Child Psychol Psychiatry 2018. Doi: $10.1111 /$ jcpp. 12945

23 Urfer-Maurer N, Weidmann R, Brand S, et al. The association of mothers' and fathers' insomnia symptoms with school-aged children's sleep assessed by parent report and in-home sleepelectroencephalography. Sleep Med 2017;38:64-70

24 Kaczor M, Skalski M. Prevalence and consequences of insomnia in pediatric population. Psychiatr Pol 2016;50(03):555-569

25 Mukherjee S, Patel SR, Kales SN, et al; American Thoracic Society ad hoc Committee on Healthy Sleep. American Thoracic Society ad hoc Committee on Healthy Sleep. An official American thoracic society statement: the importance of healthy sleep. recommendations and future priorities. Am J Respir Crit Care Med 2015;191 (12):1450-1458

26 Sivertsen B, Harvey AG, Reichborn-Kjennerud T, Torgersen L, Ystrom E, Hysing M. Later emotional and behavioral problems associated with sleep problems in toddlers: a longitudinal study. JAMA Pediatr 2015;169(06):575-582

27 Jan YW, Yang CM, Huang YS. Comorbidity and confounding factors in attention-deficit/hyperactivity disorder and sleep disorders in children. Psychol Res Behav Manag 2011;4:139-150

28 Combs D, Goodwin JL, Quan SF, Morgan WJ, Shetty S, Parthasarathy S. Insomnia, health-related quality of life and health outcomes in children: a seven year longitudinal cohort. Sci Rep 2016; 6:27921

29 Byars KC, Yeomans-Maldonado G, Noll JG. Parental functioning and pediatric sleep disturbance: an examination of factors associated with parenting stress in children clinically referred for evaluation of insomnia. Sleep Med 2011;12(09):898-905

30 Bruni O, Angriman M. Pediatric insomnia: new insights in clinical assessment and treatment options. Arch Ital Biol 2015;153 $(2,3): 144-156$

31 Ivanenko A, Barnes ME, Crabtree VM, Gozal D. Psychiatric symptoms in children with insomnia referred to a pediatric sleep medicine center. Sleep Med 2004;5(03):253-259

32 Owens JA, Spirito A, McGuinn M. The Children's Sleep Habits Questionnaire (CSHQ): psychometric properties of a survey instrument for school-aged children. Sleep 2000;23(08):1043-1051

33 Byars KC, Simon SL, Peugh J, Beebe DW. Validation of a brief insomnia severity measure in youth clinically referred for sleep evaluation. J Pediatr Psychol 2017;42(04):466-475

34 Schwerdtle B, Kanis J, Kübler A, Schlarb AA. The children's sleep comic: Psychometrics of a self-rating instrument for childhood insomnia. Child Psychiatry Hum Dev 2016;47(01):53-63

35 Crabtree VM, Ivanenko A, Gozal D. Clinical and parental assessment of sleep in children with attention-deficit/hyperactivity disorder referred to a pediatric sleep medicine center. Clin Pediatr (Phila) 2003;42(09):807-813

36 Dayyat EA, Spruyt K, Molfese DL, Gozal D. Sleep estimates in children: parental versus actigraphic assessments. Nat Sci Sleep 2011;3:115-123

37 Insana SP, Gozal D, Montgomery-Downs HE. Invalidity of one actigraphy brand for identifying sleep and wake among infants. Sleep Med 2010;11(02):191-196

38 Nelson TD, Lundahl A, Molfese DL, et al. Estimating child sleep from parent report of time in bed: development and evaluation of adjustment approaches. J Pediatr Psychol 2014;39(06):624-632 
39 Spruyt K, Gozal D, Dayyat E, Roman A, Molfese DL. Sleep assessments in healthy school-aged children using actigraphy: concordance with polysomnography. JSleep Res 2011;20(1,Pt 2):223-232

40 Honaker SM, Meltzer LJ. Bedtime problems and night wakings in young children: an update of the evidence. Paediatr Respir Rev 2014;15(04):333-339

41 Morgenthaler TI, Owens J, Alessi C, et al; American Academy of Sleep Medicine. Practice parameters for behavioral treatment of bedtime problems and night wakings in infants and young children. Sleep 2006;29(10):1277-1281

42 Blake MJ, Sheeber LB, Youssef GJ, Raniti MB, Allen NB. Systematic review and meta-analysis of adolescent cognitive-behavioral sleep interventions. Clin Child Fam Psychol Rev 2017;20(03):227-249

43 Blake M, Waloszek JM, Schwartz O, et al. The SENSE study: post intervention effects of a randomized controlled trial of a cognitive-behavioral and mindfulness-based group sleep improvement intervention among at-risk adolescents. J Consult Clin Psychol 2016;84(12):1039-1051

44 Clarke G, McGlinchey EL, Hein K, et al. Cognitive-behavioral treatment of insomnia and depression in adolescents: a pilot randomized trial. Behav Res Ther 2015;69:111-118

45 Corkum P, Lingley-Pottie P, Davidson F, et al. Better nights/better days-distance intervention for insomnia in school-aged children with/without ADHD: a randomized controlled trial. J Pediatr Psychol 2016;41(06):701-713

46 De Bruin EJ, van Steensel FJ, Meijer AM. Cost-effectiveness of group and internet cognitive behavioral therapy for insomnia in adolescents: results from a randomized controlled trial. Sleep 2016;39(08):1571-1581

47 Jansson-Fröjmark M, Norell-Clarke A. The cognitive treatment components and therapies of cognitive behavioral therapy for insomnia: a systematic review. Sleep Med Rev 2018 ( e-pub ahead of print) doi: . Doi: 10.1016/j.smrv.2018.05.001

48 Ma ZR, Shi LJ, Deng MH. Efficacy of cognitive behavioral therapy in children and adolescents with insomnia: a systematic review and meta-analysis. Braz J Med Biol Res 2018;51(06):e7070

49 Meltzer LJ, Mindell JA. Systematic review and meta-analysis of behavioral interventions for pediatric insomnia. J Pediatr Psychol 2014;39(08):932-948

50 Peterman JS, Carper MM, Elkins RM, Comer JS, Pincus DB, Kendall PC. The effects of cognitive-behavioral therapy for youth anxiety on sleep problems. J Anxiety Disord 2016;37:78-88

51 Rigney G, Ali NS, Corkum PV, et al. A systematic review to explore the feasibility of a behavioural sleep intervention for insomnia in children with neurodevelopmental disorders: a transdiagnostic approach. Sleep Med Rev 2018;41:244-254

52 Meltzer LJ. Clinical management of behavioral insomnia of childhood: treatment of bedtime problems and night wakings in young children. Behav Sleep Med 2010;8(03):172-189

53 Tikotzky L, Sadeh A. The role of cognitive-behavioral therapy in behavioral childhood insomnia. Sleep Med 2010;11(07):686-691

54 Qaseem A, Kansagara D, Forciea MA, Cooke M, Denberg TD; Clinical Guidelines Committee of the American College of Physicians. Management of chronic insomnia disorder in adults: a clinical practice guideline from the American College of Physicians. Ann Intern Med 2016;165(02):125-133

55 Ali N, Rigney G, Weiss SK, et al. Optimizing an eHealth insomnia intervention for children with neurodevelopmental disorders: a Delphi study. Sleep Health 2018;4(02):224-234

56 Corkum PV, Reid GJ, Hall WA, et al. Evaluation of an internet-based behavioral intervention to improve psychosocial health outcomes in children with insomnia (Better Nights, Better Days): protocol for a randomized controlled trial. JMIR Res Protoc 2018;7(03):e76

57 Culbert T. Perspectives on technology-assisted relaxation approaches to support mind-body skills practice in children and teens: clinical experience and commentary. Children (Basel) 2017;4(04):E20
58 Stojanovski SD, Rasu RS, Balkrishnan R, Nahata MC. Trends in medication prescribing for pediatric sleep difficulties in U.S. outpatient settings. Sleep 2007;30(08):1013-1017

59 Anand S, Tong H, Besag FMC, Chan EW, Cortese S, Wong ICK Safety, tolerability and efficacy of drugs for treating behavioural insomnia in children with Attention-Deficit/Hyperactivity Disorder: a systematic review with methodological quality assessment. Paediatr Drugs 2017;19(03):235-250

60 Bock DE, Roach-Fox E, Seabrook JA, Rieder MJ, Matsui D. Sleeppromoting medications in children: physician prescribing habits in Southwestern Ontario, Canada. Sleep Med 2016;17:52-56

61 Economou NT, Ferini-Strambi L, Steiropoulos P. Sleep-related drug therapy in special conditions: children. Sleep Med Clin 2018;13(02):251-262

62 Ivanenko A, Crabtree VM, Tauman R, Gozal D. Melatonin in children and adolescents with insomnia: a retrospective study. Clin Pediatr (Phila) 2003;42(01):51-58

63 Janjua I, Goldman RD. Sleep-related melatonin use in healthy children. Can Fam Physician 2016;62(04):315-317

64 Maras A, Schroder CM, Malow BA, Findling RL, Breddy J, Nir T, Shahmoon S, Zisapel N, Gringras P. Long-term efficacy and safety of pediatric prolonged-release Melatonin for insomnia in children with autism spectrum disorder. J Child Adolesc Psychopharmacol 2018. Doi: 10.1089/cap.2018.0020

65 van Maanen A, Meijer AM, Smits MG, van der Heijden KB, Oort FJ. Effects of Melatonin and bright light treatment in childhood chronic sleep onset insomnia with late Melatonin onset: a randomized controlled study. Sleep 2017;40(02):

66 Zwart TC, Smits MG, Egberts TCG, Rademaker CMA, van Geijlswijk IM. Long-term melatonin therapy for adolescents and young adults with chronic sleep onset insomnia and late Melatonin onset: evaluation of sleep quality, chronotype, and lifestyle factors compared to age-related randomly selected population cohorts. Healthcare (Basel) 2018;6(01):E23

67 Gringras P, Nir T, Breddy J, Frydman-Marom A, Findling RL. Efficacy and safety of pediatric prolonged-release Melatonin for insomnia in children with autism spectrum disorder. J Am Acad Child Adolesc Psychiatry 2017;56(11):948-957.e4

68 Malow B, Adkins KW, McGrew SG, et al. Melatonin for sleep in children with autism: a controlled trial examining dose, tolerability, and outcomes. J Autism Dev Disord 2012;42(08):1729-1737 , author reply 1738

69 Bruni O, Angriman M, Calisti F, et al. Practitioner review: treatment of chronic insomnia in children and adolescents with neurodevelopmental disabilities. J Child Psychol Psychiatry 2018;59(05):489-508

70 Blackmer AB, Feinstein JA. Management of sleep disorders in children with neurodevelopmental disorders: a review. Pharmacotherapy 2016;36(01):84-98

71 de Bruin EJ, Bögels SM, Oort FJ, Meijer AM. Efficacy of cognitive behavioral therapy for insomnia in adolescents: a randomized controlled trial with internet therapy, group therapy and a waiting list condition. Sleep 2015;38(12):1913-1926

72 Hagatun S, Vedaa Ø, Nordgreen T, et al. The short-term efficacy of an unguided internet-based cognitive-behavioral therapy for insomnia: a randomized controlled trial with a six-month nonrandomized follow-up. Behav Sleep Med 2017. Doi: 10.1080/ 15402002.2017.1301941

73 Mindell JA, Du Mond CE, Sadeh A, Telofski LS, Kulkarni N, Gunn E. Long-term efficacy of an internet-based intervention for infant and toddler sleep disturbances: one year follow-up. J Clin Sleep Med 2011;7(05):507-511

74 Sato D, Yoshinaga N, Nagai E, Hanaoka H, Sato Y, Shimizu E. Randomised controlled trial on the effect of internet-delivered computerised cognitive-behavioural therapy on patients with insomnia who remain symptomatic following hypnotics: a study protocol. BMJ Open 2018;8(01):e018220 